\title{
GÜÇ KALİTESİ PROBLEMLERİNİ DÜZELTEN DAĞITIM SİSTEMİNE PARALEL BAĞLI EVİRİCI TABANLI KOMPANZATÖRLERİN İNCELENMESİ
}

\author{
Mohammad BARGHI LATRAN", Ahmet TEKE \\ Elektrik-Elektronik Mühendisliği Bölümü, Çukurova Üniversitesi, Adana \\ mbarghi@student.cu.edu.tr, ahmetteke@cu.edu.tr
}

(Geliş/Received: 08.02.2014; Kabul/Accepted: 08.07.2014)

ÖZET

\begin{abstract}
Elektrik enerjisi piyasasındaki serbestleşmeyle birlikte, güç kalitesi problemleri elektrik enerjisi üreten firmalar ve son kullanıcı müşteriler için ciddi bir endişe sebebi olmaktadır. Son yıllarda, şebekedeki güç kalitesi problemlerinin düzeltilmesinde geleneksel kompanzasyon cihazları yetersiz kaldığından, ileri teknoloji güç elektroniği tabanlı kompanzasyon cihazlarının geliştirilmesine gereksinim duyulmuştur. Bu çalışmada Dağıtım Sistemi Statik Senkron Kompanzatörü (DSTATKOM) ve Aktif Güç Filtresi (AGF) gibi dağıtım sistemine paralel bağlı Özel Güç Cihazı (ÖGC) kompanzatörlerinin ayrıntılı bir incelemesi sunulmuştur. Güç sistemlerinde karşılaşılan farklı güç kalitesi problemlerini kompanze eden DSTATKOM ve AGF'ler için kullanılan farklı kontrol yöntemleri ve bu cihazların temel çalışma prensipleri üzerine geniş bir literatür taraması hazırlanmıştır. Yaklaşık 120 makale incelenerek DSTATKOM ve AGF üzerine yapılmış pratik uygulamalar ve son araştırma gelişmeleri sunulmuştur.
\end{abstract}

Anahtar Kelimeler: Güç kalitesi problemleri, Evirici tabanlı paralel kompanzatör, DSTATKOM, AGF.

\section{INVESTIGATION OF INVERTER BASED SHUNT COMPENSATORS FOR MITIGATION OF POWER QUALITY PROBLEMS IN POWER DISTRIBUTION SYSTEM}

\begin{abstract}
Power quality (PQ) problems have become a serious concern of both power suppliers and end user customers with the deregulation of the electric power market. In the recent years, power electronics based compensation devices with advanced technology has been required due to the inadequate of conventional compensation devices to improve PQ in utility grid. This paper presents a comprehensive review of shunt compensating custom power devices (CPD) connected to distribution system mainly Distribution Synchronous Static Compensator (DSTATCOM) and Active Power Filter (APF). A broad overview on various control methods to compansate different PQ problems used in DSTATCOM and APF's and the main operation principles of these devices are provided. The practical applications and recent research advances on DSTATCOM and APF's are presented by reviewing nearly 120 papers.
\end{abstract}

Keywords: Power quality problems, Inverter based shunt compensator, DSTATCOM, APF.

\section{GÍRISŞ (INTRODUCTION)}

Elektrik enerjisine olan ihtiyacın gün geçtikçe artması ve gelişen güç elektroniği teknolojisi ile elektrik sistemine bağlı yüklerin karakteristiklerindeki hızlı değişimler, elektrik güç sistemlerinde elektrik güç kalitesi ve elektrik enerjisi verimliliği gibi konularının önem kazanmasına sebep olmaktadır. Elektrik güç sistemine bağlı cihazların ve son kullanıcı yüklerin zarar görmesine, arızalanmasına veya istenmeyen bir çalışma karakteristiğine neden olan gerilimin veya akımın genliğindeki, frekansındaki ve dalga formundaki değişimler, elektrik güç kalitesi problemleri olarak tanımlanmaktadır. Güç kalitesizliği yaşayan elektriksel şebekelerde maddi kayıplardan, çevreye olumsuz etkilerden ve güvenilirlik problemlerinden bahsedilebilir. İdeal bir alternatif akım şebekesinin güç kalitesi; (i) Faz gerilimi ve faz akımlarının dengeli olması, (ii) Güç faktörünün 1'e yakın olması, (iii) Gerilimin ve frekansın sabit olması, (iv) Kesintisiz elektrik enerjisi verilmesi ve (v) Harmonik oranının belirli sınırlar içerisinde kalması 
ile tanımlanabilir [1]. Bir elektrik sinyalini (gerilim ve akım) kaliteli olarak nitelendirebilmek için sinyalin güç kalitesi parametrelerinin ulusal veya uluslararası standartlara olan uygunluğuna bakılır. Uluslararası standartlarda elektrik güç kalitesi problemleri güç sistemlerindeki elektromanyetik olaylar olarak belirtilmektedir ve IEC 61000-2-5, IEC 61000-2-1, IEC 61000-4-30 ve IEEE Std.1159'da tanımlanmıştır. Ulusal standartlarda ise TS EN 50160:2011 ve TS EN 61000-4-30'da belirtilmiştir. Bu standartlarda gerilim bozulmaları; gerilimin etkin değerinin değişimi, kırpışma, ani değişimler, akım veya gerilim harmonik bozulmaları ve dengesizlikleri olarak beş ana gruba ayrılır [2], [3]. Bir elektrik güç sisteminde gerilimin genliği; güç sistemine reaktif güç vererek veya güç sisteminden reaktif güç çekerek kontrol edilebilir. Senkron jeneratörler, mekanik anahtarlamalı kondansatörler-endüktanslar ve doyumlu reaktörler; sistem gerilimini bu yöntemle kontrol etmek için uzun süreden beri iletim ve dağıtım sistemlerinde kullanılmaktadır. Ancak bu geleneksel kondansatör ve reaktör grupları ile yapılan kompanzasyon sisteminin meydana gelen değişimlere yeterince hılı cevap verememesi gibi büyük bir dezavantajı vardır. Zaman içerisinde yariiletken anahtar teknolojisindeki gelişmeler ve güç kalitesine olan artan ilgi, gerilim dalga şeklinin kalitesini iyileştirmek için şebekeye bağlanan birçok donanımın geliştirilmesine neden olmuştur. $\mathrm{Bu}$ donanımlar; modern güç elektroniği tabanlı Esnek Alternatif Akım İletim Sistemleri (EAAİS) olarak bilinir. İlk geliştirilen EAAİS aygitları; Tristör Kontrollü Reaktör (TKR) veya Tristör Anahtarlamalı Kondansatör (TAK) kullanan geleneksel Statik VAr Kompanzatörlerdir (SVK). SVK sistemleri reaktif güç problemini çözerken harmonikli akım problemlerine neden olmaktadır. $\mathrm{Bu}$ durumun çözümü; bu sistemler için maliyet ve boyut artışına sebep olan, sabit paralel filtreler veya özel transformatör bağlantılarını gerektirir. En son geliştirilen EAAİS aygıtları ise evirici tabanlıdır. Bunların en çok kullanılanları STATKOM, Statik Senkron Seri Kompanzatör (SSSK) ve Birleştirilmiş Güç Akış Kontrolcü (BGAK)'dür. Dağıtım şebekelerinde kullanılan EAAİS aygıtları ise ÖGC olarak adlandirılmakta olup; bu cihazlar AGF, Dinamik Gerilim İyileştirici, Birleştirilmiş Güç Kalitesi Düzenleyici (BGKD) ve DSTATKOM'dur [4-5].

Paralel bağlı ÖGC'ler son yıllardaki çalışmalarda, gerilim çukuru, gerilim tepesi, akım ve gerilim harmonikleri, akım ve gerilim dengesizlikleri, gerilim dalgalanması, geçici rejim olaylarının sönümlendirilmesi gibi birçok güç kalitesi problemlerinin bazılarını ve reaktif gücü kompanze edebilecek şekilde geliştirilmiştir. Paralel bağlı ÖGC'lerde temel kontrol parametreleri, uygulamaların işletme gerekliliklerine, türüne, sistem konfigürasyonuna ve kayıp optimizasyonuna dayalı istenilen performansı elde etmek için kontrol edilir.
Paralel bağlı ÖGC'ler kontrol sisteminin tasarımı ve uygulaması işleminde, birçok sinyalin elde edilmesi gerekmektedir. Şekil 1'den de görüldüğü gibi, ilk olarak gerekli olan AA ve DA gerilim ve akım sinyalleri (ani değerler/vektörler) sensörler kullanılarak algılanır. $\mathrm{Bu}$ sinyaller $\mathrm{d}-\mathrm{q}$ eşzamanlı dönen eksen dönüşümü, alfa-beta dönüşümü ve sabit referans çerçevesi gibi teknikler kullanılarak bileşenlerine ayrıştırılır. Üçüncü adımda, son teknoloji kontrol yöntemleri, lineer, lineer olmayan veya özel kontrol teknikleri kullanılarak kompanzasyon sinyallerinin üretimi sağlanır. Dördüncü adımda, yarı iletken cihazlarının çalışması için gerekli olan anahtarlama sinyalleri üretilir [6-7].

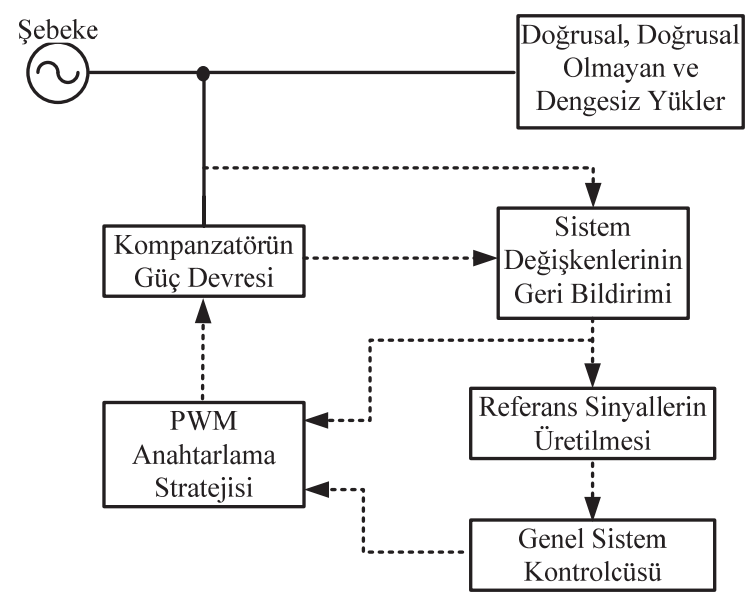

Şekil 1. Paralel ÖGC'lerin temel bileşenleri (Main components of shunt $\mathrm{CPD}$ )

$\mathrm{Bu}$ çalışma güç kalitesi problemlerini düzelten dağıtım sistemine paralel bağlı evirici tabanlı kompanzatörlerin incelenmesi üzerine olup, DSTATKOM ve AGF'lerin kompanzasyon yetenekleri ve bu kompanzatörlerin kontrol sistemleriyle ilgili bilgiler sırasıyla Bölüm 2 ve 3 'te sunulmuştur. Çalışmanın önemli, sonuçları ve tartışmaları sonuç bölümünde belirtilmiştir.

\section{DSTATKOM'UN ÇALIŞMA PRENSİBİ VE KONTROL YÖNTEMLERI (OPERATION PRINCIPLE AND CONTROL METHODS OF DSTATCOM)}

STATKOM boşta dönen bir senkron motor olan ve senkron kondenser olarak bilinen reaktif güç kompanzasyon sisteminin güç yarı iletkenleri kullanılarak düzenlenmiş statik eşdeğeridir. STATKOM, hem endüktif, hem de kapasitif bölgede reaktif güç üretebilmekte olup elektrik sisteminin veya yükün reaktif güç istemindeki değişmelere çok hızlı cevap verebilme yeteneğine sahiptir (5- birkaç $100 \mathrm{~ms}$ ). Bu açıdan alternatif sistem olan SVK'lara üstünlük sağlamaktadır. STATKOM sisteminin SVK sisteminden bir diğer üstünlüğü ise geniş bir çıkış gerilimi aralığı için maksimum reaktif güç üretiminin neredeyse sabit kalmasıdır. STATKOM sistemlerinin temel işlevleri şöyle özetlenebilir [8]: 1) Reaktif güç 
akışının kontrol edilmesi, 2) Bağlandığı noktadaki gerilimin düzenlenmesi, 3) Elektrik sisteminde geçici rejim ve dinamik kararlılık sınır değerlerinin arttırılmasi.

STATKOM, dağıtım sistemlerinde gerilim regülasyonu, güç faktörünü düzeltme, yük dengeleme ve harmonik kompanzasyonu için kullanılmakta olup DSTATKOM olarak adlandırılmaktadır. Ayrıca, pasif elemanlar ile birleştirilmiş şekilde melez kompanzatör cihazları olarak ta kullanılabilmektedir. DSTATKOM'un çeşitli çalışma şartları altında hızlı cevap verme süresi, daha az alan gereksinimi, optimum gerilim platformu, daha yüksek çalışma esnekliği ve mükemmel dinamik karakteristiği önemli özelliklerindendir. DSTATKOM teknolojisi kararlı hal ve dinamik sistem şartlarında güç sistemi parametrelerini kontrol etmek için çok amaçlı uygulamalara sahiptir [7].

Şekil 2'de gösterildiği gibi DSTATKOM genellikle, bir bağlantı transformatörü, bir evirici ve bir doğru gerilim enerji depolama aygıtından (kondansatör) meydana gelir. Evirici, dolu bir kondansatörün sağladığı doğru gerilimi, güç sistemi ile aynı frekansta, genliği ve faz açısı hızlı bir şekilde kontrol edilebilir üç fazlı alternatif bir çıkış gerilimine dönüştürür ve şebekeye bir bağlantı transformatörü yardımı ile bağlanır [10]. DSTATKOM tarafından üretilen çıkış geriliminin genliği, evirici ile güç sistemi arasındaki reaktif güç alışverişini belirler. Eviricinin ürettiği çıkış geriliminin genliği bara geriliminin genliğinden fazla ise, akım bağlantı

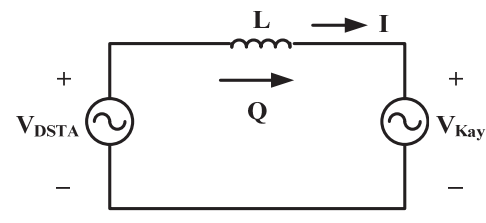

(a)

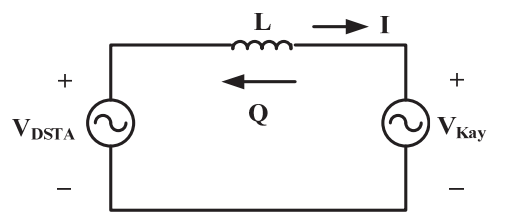

(b)

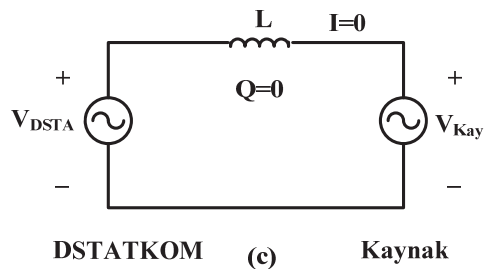

transformatörünün kaçak reaktansı yardımı ile dönüştürücüden baraya doğru akar ve dönüştürücü, sistem için kapasitif reaktif güç üretir. Eviricinin ürettiği çıkış geriliminin genliği bara geriliminin genliğinden küçük olması durumunda akım baradan eviriciye doğru akar ve evirici endüktif reaktif güç tüketir. Eviricinin çıkış gerilimi ve bara geriliminin genliğinin birbirlerine eşit olduğu durumda reaktif güç alışverişi olmayacaktır. DSTATKOM'un çalışma prensibi ve fazör diyagramları Şekil 3'te gösterilmiştir [7], [9].

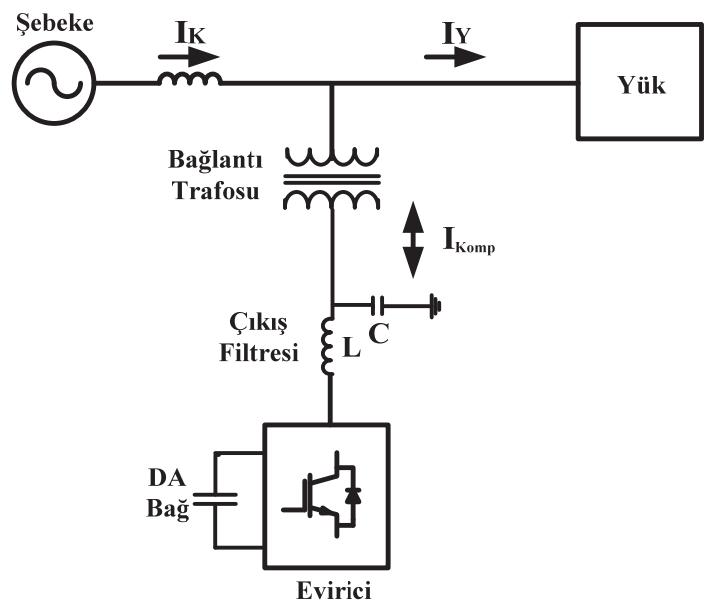

Şekil 2. DSTATKOM'un tek hat şeması (Single line diagram of DSTATCOM)

Evirici ile güç sistemi arasındaki aktif güç değişimi; DSTATKOM'un bağlı bulunduğu baranın gerilimi ile

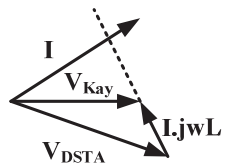

(d)

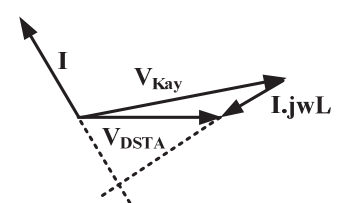

(e)

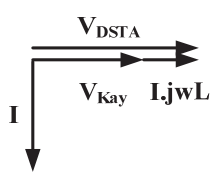

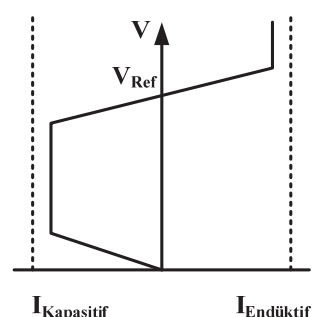

(f)

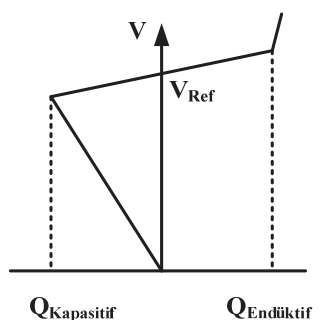

(h)

Şekil 3. DSTATKOM'un temel çalışma prensibi ve vektör diyagramları, (a) Kapasitif modu, (b) Endüktif mı (c) Durağan modu, (d) Kapasitör şarj modu, (e) Kapasitör deşarj modu, (f) V-I karakteristiği, (h) V-Q karakteris [7]. (The main operation principle and vector diagrams of DSTATCOM, (a) Capacitive mode, (b) Inductive mode, (c) Floating mode Capacitor charging mode, (e) Capacitor decharging mode, (f) V-I characteristics, (h) V-Q characteristics) 
eviricinin çıkış gerilimi arasındaki faz farkı ayarlanarak kontrol edilebilir. Eviricinin çıkış gerilimi bara geriliminden ileri fazda olacak şekilde kontrol edilirse, evirici kendi doğru gerilim enerji deposundan sisteme aktif güç sağlar. Eğer eviricinin çıkış gerilimi bara geriliminden geri fazda olursa, bu durumda dönüştürücü, şebekeden aktif güç çekecektir. DSTATKOM 'un ürettiği/tükettiği reaktif güç miktarı,

$Q=\frac{V}{X}\left(V-V_{o} \operatorname{Cos} \psi\right)$

ile ifade edilir. DSTATKOM'un sisteme verdiği veya sistemden aldığı aktif güç miktarı,

$P=\frac{V V_{o}}{X} \operatorname{Sin} \psi$

şeklinde yazılır. Burada $V$ bara gerilimi, $V_{o}$ eviricinin çıkış gerilimi, $X$ bağlantı transformatörünün kaçak reaktansı ve $\phi$ ise DSTATKOM'un bağlı bulunduğu baranın gerilimi ile eviricinin çıkış gerilimi arasındaki faz farkıdır. Sürekli durumda, eviricinin çıkış gerilimi, bara geriliminden geri fazda tutularak, aktif güç akışının güç sisteminden eviriciye doğru olması sağlanır $\quad(\mathrm{P}>0) . \quad \mathrm{Bu}$ durumda eviricide ve transformatörde meydana gelen kayıplar güç sisteminden karşılanır [9].

DSTATKOM'daki son gelişmeler birden fazla güç kalitesi problemini eş zamanlı olarak düzeltebilmektedir veya problemin önemine göre çalışma modunu değiştirerek (örneğin gerilim kontrol modundan akım harmoniği eleme moduna geçiş yapılması) bu problemlerin bazılarını kompanze etmektedir. Tablo 1'de dağıtım seviyesinde farklı güç kalitesi problemlerini düzeltmek için kullanılan tek ve iki farklı modda çalışan DSTATKOM çalışmaları gösterilmiştir. DSTATKOM sistemlerinin kontrolündeki en önemli işlemlerden biri olan kompanzasyon sinyalleri genelde zaman ya da frekans ortamında üretilir. Ani gerilim ve/veya akım vektörlerinin zaman alanı sinyalleri algılanır ve bu sinyaller d-q eş zamanlı dönen eksen dönüşümü [20], [25], [28], [33], [38]-[40], [65] ve pq [14], [21], [29], [30], [34], [36], [43], [44], [48] gibi yöntemler kullanılarak bileşenlerine ayrıştırılır. Dönüşen değerler kompanzasyon sinyallerini üretmek için oransal-doğrusal (PI) veya oransal-doğrusal-türevsel (PID) denetleyiciler gibi kontrol teknikleri kullanılarak işlenir. Referans sinyalinin üretilmesi için geri yayılım [10], karma gözlemci tabanlı [16],

Tablo 1. Farklı güç kalitesi problemlerini düzelten DSTATKOM çalışmaları (DSTATCOM studies used to compensate different power quality problems)

\begin{tabular}{ll}
\hline \hline \multicolumn{1}{c}{ Kompanze edilen güç kalitesi problemleri } & \multicolumn{1}{c}{ Tek modda çalışan kompanzatörler } \\
\hline \hline Reaktif güç kompanzasyonu & 28,38 \\
\hline Gerilim kontrolü & $26,47,49,57,61$ \\
\hline Gerilim çukuru kompanzasyonu & 32 \\
\hline Akım harmoniklerinin kompanzasyonu & 37 \\
\hline Gerilim çukuru ve kırpışması & 66 \\
\hline Reaktif güç kompanzasyonu ve gerilim kontrolü & $13,18,31,65$ \\
\hline Reaktif güç ve gerilim çukuru kompanzasyonu & 33 \\
\hline Reaktif güç ve dengesiz yüklerin kompanzasyonu & 39,58 \\
\hline Reaktif güç ve akım harmoniklerinin kompanzasyonu & $34,35,40$ \\
\hline Gerilim kontrolü ve gerilim harmoniği kompanzasyonu & 64 \\
\hline Gerilim ve faz açısı kontrolü & 67 \\
\hline Akım harmonikleri ve dengesiz yüklerin kompanzasyonu & $20,23,54,55,56,68$ \\
\hline Akım harmonikleri ve nötr akımının kompanzasyonu & 22 \\
\hline Dengesiz yükler ve nötr akımının kompanzasyonu & 21 \\
\hline Gerilim regülasyonu ve dengelenmesi & 49 \\
\hline Reaktif güç, akım harmonikleri ve dengesiz yüklerin kompanzasyonu & $11,16,17,25,44,63$ \\
\hline $\begin{array}{l}\text { Reaktif güç, akım harmonikleri, yük dengeleme ve nötr akımının } \\
\text { kompanzasyonu }\end{array}$ & 24 \\
\hline $\begin{array}{l}\text { Reaktif güç, akım harmonikleri, dengesiz yüklerin kompanzasyonu ve } \\
\text { gerilim kontrolü }\end{array}$ & 27 \\
\hline \hline
\end{tabular}
gerilim kontrolü

\section{İki farklı modda çalışan kompanzatörler}

Gerilim çukuru veya akım harmoniklerinin kompanzasyonu 41

Gerilim dengesizliği veya akım harmonikleri ve dengesiz yüklerin 69

kompanzasyonu

Reaktif güç, akım harmonikleri ve dengesiz yüklerin kompanzasyonu

veya sıfır gerilim regülasyonu

$15,10,14,36,43$

Reaktif güç, akım harmonikleri, dengesiz yüklerin ve nötr akımının

kompanzasyonu veya sifır gerilim regülasyonu 
vektör kuantalamalı öğrenme [17], uyarlamalı eş-zamanlı referans çıkarma [26], [27], [67], yapay sinir ağları tabanlı üçgen fonksiyon karakteri [29], Adaline tabanlı yapay sinir ağları [58] ve Kalman filtre [66] kullanılmıştır.

Oluşan hataların kompanzasyonunda ve gerilim regülasyonunda çeşitli anahtarlama durumlarını belirleyen akım kontrol teknikleri, doğrusal ve/veya doğrusal olmayan kontrol stratejileri ile gerçekleştirilir. Doğrusal kontrol yöntemlerinde PI denetleyici veya rampa karşılaştırmalı akım kontrol, eşzamanlı vektör PI kontrol, durum geri beslemeli kontrol [61], kestirimci kontrol ve deadbeat kontrol yöntemleri kullanılmaktadır [46]. Doğrusal olmayan denetleyicilerde ise histeresis kontrol [38], [55], [56], [63], yapay sinir ağları [32], bulanık mantık [34], admittans tabanlı algoritmalar [36], serbest-model bazlı kestirimci [31], kayan kip [54], [64], melez genetik algoritma tabanlı uyarlamalı [26], gelişmiş lineer sinüs izleyici tabanlı uyarlamalı [15], yapay bağışıklık sistemi [49], delta modülasyon (DM) veya darbe DM akım kontrol ve çevrimiçi optimize edilmiş yöntemleri kullanılmıştır.

Literatürde DSTATKOM ile ilgili çalışmalarda sistemin performansının iyileştirilmesi, kararlı çalışmasının sağlanması, farklı elektrik güç kalitesi problemlerinin kompanzasyonunun sağlanmas1, maliyetinin düşürülmesi, boyutlarının küçültülmesi ve modülerliğinin arttırılması gibi amaçlar için hem farklı topolojiler hem de farklı kontrol yöntemleri geliştirilmiştir. DSTATKOM için öne sürülen en önemli dezavantaj olan yüksek sistem maliyeti, güç elektroniği bileşenlerinin maliyetlerinin düşmesine paralel olarak azalmaktadır. Bu gelişme ile birlikte DSTATKOM'ların ticari anlamda kullanımı daha da yaygınlaşacaktır. Tablo 2'de farklı güçlerde kurulmuş olan DSTATKOM sistemleri ve kurulu güçleri gösterilmiştir.

\section{AGF'NIN CALISSMA PRENSİİ VE KONTROL YÖNTEMLERİ (OPERATION PRINCIPLE AND CONTROL METHODS OF APF)}

Harmonikler, gerilimdeki veya akımdaki, sistemin temel bileşen frekansının tam sayı katlarındaki frekansa sahip sinüzoidal gerilimler veya akımlar olarak tanımlanmaktadır. Gelişen teknolojiyle ve güç elektroniği alanındaki gelişmeler ile elektrik motorları, rezistif 1sitıcılar ve fırınlar gibi doğrusal yükler yerini; motor sürücüleri, endüksiyon firınları, AA/DA güç kaynağına sahip elektronik cihazlar, kesintisiz güç kaynakları, elektronik balastlı aydınlatma sistemleri gibi doğrusal olmayan yüklere bırakmaktadır. Bu yükler birçok uygulamada tasarruf sağlamalarına karşın yük karakteristiklerinden dolayı akım harmonikleri ve bu harmoniklerinin elektrik şebekesinde yol açtığı gerilim düşümleri nedeniyle gerilim harmoniklerini meydan getirmektedir [74].
Dalga formunda harmoniklerin yol açtığı bozulma miktarı, toplam harmonik bozulması (THB) ile belirlenmektedir. Gerilim ve akım dalga formları için THB, Denklem 3 ve 4'te gösterildiği gibi, harmonik bileşenlerin etkin değerlerinin toplamının karekökünün temel bileşenin rms değerine oranının yüzde değeri ile ifade edilmektedir.

Tablo 2. DSTATKOM'ların kurulu güç kapasiteleri (Installed power capacities of DSTATCOMs)

\begin{tabular}{|c|c|c|}
\hline Referans & Kapasite & Uygulama \\
\hline [68] & $-500 / 750 \mathrm{kVAr}$ & Linyit madenciliği \\
\hline [69] & $\pm 750 \mathrm{kVAr}$ & Linyit madenciliği \\
\hline$[68]$ & $-5100 / 0 \mathrm{kVAr}$ & $\begin{array}{l}\text { Konveyor motoru } \\
\text { sürücüsü }\end{array}$ \\
\hline$[70]$ & $3 \mathrm{MVAr}$ & Galvanizleme işlemi \\
\hline$[72]$ & $3 \mathrm{MVAr}$ & Çelik fabrikası \\
\hline$[70]$ & 4.5 MVAr & $\begin{array}{l}\text { Uzun dağıtım } \\
\text { kabloları }\end{array}$ \\
\hline$[73]$ & $4.5 \mathrm{MVAr}$ & Madencilik \\
\hline [72] & $2 \times 4.5 \mathrm{MVAr}$ & Çelik fabrikası \\
\hline$[70]$ & $5.5 \mathrm{MVAr}$ & Ağır yükler \\
\hline [70] & $12 \mathrm{MVAr}$ & Uzun dağıtım hattı \\
\hline [70] & $12 \mathrm{MVAr}$ & Rüzgâr türbinleri \\
\hline$[70]$ & $\pm 15 \mathrm{MVAr}$ & Rüzgâr türbinleri \\
\hline [71] & $24 \mathrm{MVAr}$ & Rüzgâr türbinleri \\
\hline
\end{tabular}

$T H B_{V}=\frac{\sqrt{\sum_{k=2} V_{k}^{2}}}{V_{1}} \times 1$

$T H B_{I}=\frac{\sqrt{\sum_{k=2} I_{k}^{2}}}{I_{1}} \times 100 \%$

Akım harmoniklerinin güç sistemine etkilerinin THB ile hesaplanması tam olarak doğru olmayabilir. Bu nedenle, doğrusal olmayan yükün şebekeye etkisi, yükün gücü ve meydana getirdiği akım harmonikleri ile ilgili olduğundan, akım harmoniklerinin şebekeye etkisi IEEE Std.519-1992 standardında belirtilen toplam talep bozulumu (TTB) ile belirlenir. TTB, Denklem 5'de verildiği gibi harmonik bileşenlerin etkin değerlerinin toplamının karekökünün, ortak bağlantı noktasından çekilen maksimum talep akımının temel bileşenine $\left(\mathrm{I}_{\mathrm{L}}\right)$ oranın yüzde değeri ile ifade edilmektedir $[3,75]$.

$T T B_{I}=\frac{\sqrt{\sum_{k=2} I_{k}^{2}}}{I_{L}} \times 100 \%$

Harmoniklerin elenmesi için pasif ve aktif filtreleme yöntemleri kullanılabilmektedir. Pasif filtrelerin yetersiz performansları ve rezonans oluşturma gibi dezavantajları sebebiyle AGF olarak adlandırılan güç elektroniği tabanlı aktif filtreleme sistemleri geliştirilmiştir. AGF'ler harmonik filtreleme özelliğinin yanısıra harmonik sönümleme, akım ve gerilim dengesizliği kompanzasyonu, gerilim dalgalanması ve gerilim kırpışması kompanzasyonu 
ve reaktif güç kompanzasyonu gibi birçok işlevi gerçekleştirebilmektedir. AGF'lerin güç devresi temel olarak evirici, DA bağı, giriş filtresi ve bazı uygulamalarda gerekli olması durumunda şebekeye bağlantıyı sağlayan transformatörden oluşmaktadır. AGF'ler topolojilerine göre paralel ve seri olmak üzere ikiye ayrılmaktadır. Seri AGF şebekeye seri bağlı olmasından dolayı yük akımının tamamına maruz kalmaktadır. Bu durum sistemin kapasitesini ve kayıplarını arttırmakla beraber sistemin korumasını zorlaştırmaktadır. Bu sebeple seri AGF'ler pratik uygulamalarda tercih edilmemektedir [76]. Paralel AGF uygulamada yaygın bir şekilde kullanılmakta olup, darbe genişlik modülasyonu sinyaliyle bir akım kaynağı olarak denetlenen gerilim kaynaklı bir eviriciyi temsil eder [77]. Paralel AGF'nin temel çalışma prensibi Şekil 4'te görüldüğü gibi doğrusal olmayan yüklerin ürettiği harmonik akımları tespit edip, tersini şebekeye basarak şebeke akımının sinüzoidal dalga şekline sahip olmasını sağlamaktır.

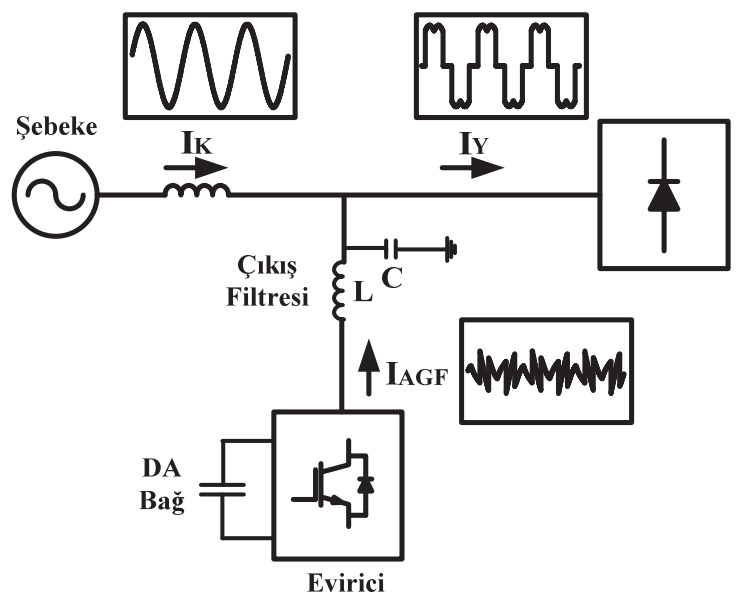

Şekil 4. Paralel AGF'nin tek hat şeması ve temel çalışma prensibi (The single line diagram and main operation principle of shunt APF)

AGF etkin bir kompanzasyon sistemi olmasına karşın artan güç kapasitesiyle doğru orantılı olarak maliyetleri de ciddi bir şekilde artmaktadır. $\mathrm{Bu}$ duruma çözüm olarak, AGF ile pasif filtreler birlikte kullanılarak melez aktif güç filtreleri geliştirilmiştir. Melez aktif güç filtreleri doğrusal olmayan yüklerin oluşturduğu baskın harmoniklerin filtrelenmesine ek olarak, reaktif güç ihtiyacını pasif filtreler ile sağlayarak AGF'nin kapasitesini ve dolayısıyla maliyetlerini düşürmektir. Şekil 5 'te şebekeye paralel bağlı farklı melez AGF topolojileri sunulmuştur [76]. Paralel AGF'ler harmonik filtreleme özelliğinin yanında yük dengesizliği ve reaktif güç kompanzasyonu gibi birçok işlevleri gerçekleştirmektedir. Literatürde farklı yük durumlarına ve farklı kompanzasyon stratejilerine göre birçok paralel AGF sistemi geliştirilmiştir. Tablo 3 'te paralel AGF çalışmaları ve kompanze ettiği güç kalitesi problemleri sunulmuştur.

Paralel AGF'de kompanzasyon sinyalleri genelde zaman ya da frekans ortamında üretilir. Ani gerilim ve/veya akım vektörlerinin zaman alanı sinyalleri algılanır ve bu sinyaller genelde d-q eş zamanlı dönen eksen [79], [86], [91], [93], [101] ve p-q [85], [88], [92] dönüşümü yöntemler kullanılarak bileşenlerine ayrıştırılır. Ayrıca literatürde AGF ile ilgili referans sinyalinin üretilmesi için modifiye edilmiş uyarlamalı çentik filtre [82], Adaline tabanlı yapay sinir ağları yöntemi [83], [89], değişken adım uzunluğu tabanlı en küçük kareler [84], modifiye edilmiş eş zamanlı referans çerçevesi [94], yapay sinir ağları [102] ve özyinelemeli oransal algoritma [90] yöntemleri kullanılmıştır. Literatürde AGF'ler genelde kalıcı durum güç kalite problemlerinin giderilmesi için kullanılmıştır. $\mathrm{Bu}$ amaçla çeşitli anahtarlama durumlarını belirleyen akım kontrol teknikleri, doğrusal ve/veya doğrusal olmayan kontrol stratejileri gerçekleştirilmiştir. Doğrusal kontrol yöntemlerinde PI denetleyici veya rampa karşılaştırmalı akım kontrol, eşzamanlı vektör PI kontrol, durum kestirimci [79], abc tabanlı [87], tek harmonik tekrarlamalı [89], gelişmiş deadbeat tabanlı [107] ve

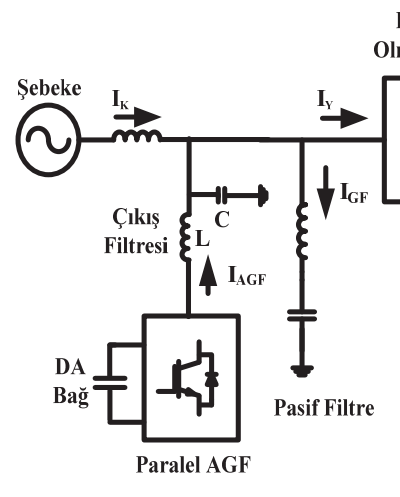

(a)

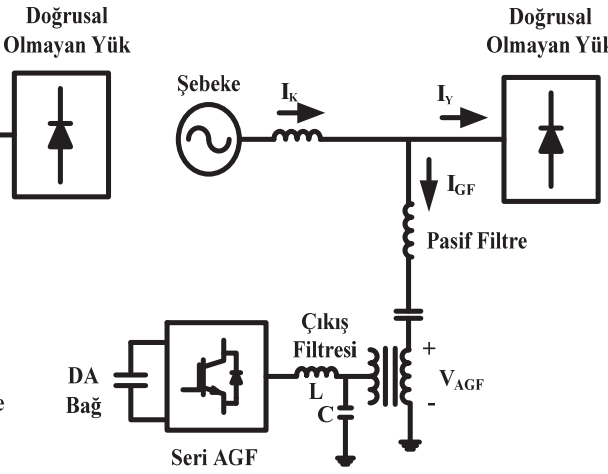

(b)

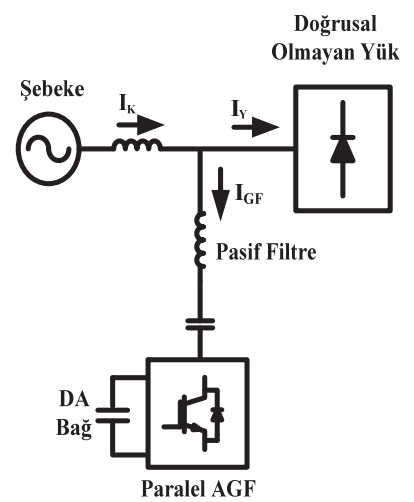

(c)

Şekil 5. Şebekeye paralel bağlı melez AGF topolojileri: (a) Paralel AGF’ye paralel bağlı pasif filtre, (b) Seri AGF'ye seri bağlı pasif filtre, (c) Paralel AGF'ye seri bağlı pasif filtre. (Hybrid APF topologies connected in shunt to the grid: (a) Passive filter connected in parallel to shunt APF, (b) Passive filter connected in series to series APF, (c) Passive filter connected in series to shunt APF) 
Tablo 3. Farklı güç kalitesi problemlerini düzelten AGF çalışmaları (APF studies used to compensate different power quality problems)

\begin{tabular}{ll}
\hline \hline Kompanze edilen güç kalitesi problemleri & Referans numarası \\
\hline \multirow{2}{*}{ Akım harmoniklerinin kompanzasyonu } & $\begin{array}{l}83,84,86,87,89,90,94,96,99,100, \\
101-103,106-108\end{array}$ \\
\hline Gerilim harmoniklerinin kompanzasyonu & $111-113$ \\
\hline Reaktif güç kompanzasyonu ve gerilim regülasyonu & 78 \\
\hline Reaktif güç ve akım harmoniklerinin kompanzasyonu & $80,81,85,92,98,104$ \\
\hline Faz gecikmesi ve akım harmoniklerinin kompanzasyonu & 79 \\
\hline Akım harmonikleri ve dengesiz yüklerin kompanzasyonu & 88 \\
\hline Harmonik bastırımı ve gerilim regülasyonu & 109 \\
\hline Akım ve gerilim harmoniklerinin kompanzasyonu & 110,115 \\
\hline $\begin{array}{l}\text { Reaktif güç, akım harmonikleri ve dengesiz yüklerin } \\
\text { kompanzasyonu }\end{array}$ & $82,91,93$ \\
\hline Reaktif güç, akım harmonikleri ve nötr akımının kompanzasyonu & 105 \\
\hline
\end{tabular}

deadbeat tabanlı kestirimci [96] kontrol yöntemleri kullanılmaktadır. Doğrusal olmayan denetleyiciler ise histeresis kontrol [81], [82], [95], uyarlamalı bulanık histeresis [80], kayan kip [86] uyarlamalı kutup yerleşimli [98], Lyapunov fonksiyon [99], melez uyarlamalı bulanık mantık tabanlı histeresis [103], yüksek dereceli tekrarlanan [104], bulanık mantık tabanlı [90], [106], tekrarlanan öğrenme tabanlı geniş bant [100] ve değişken örnekleme frekanslı tekrarlanan öğrenme [108] kontrol yöntemleri kullanılmaktadır. Tablo 4'te farklı güçlerde kurulmuş olan AGF'ler ve kurulu güçleri gösterilmiştir.

Tablo 4. Paralel AGF'lerin kurulu güç kapasiteleri (Installed power capacities of shunt APFs)

\begin{tabular}{lll}
\hline \hline Referans & Kapasite & Uygulama \\
\hline \hline$[115]$ & $154 \mathrm{kVA}$ & Teleferik \\
{$[115]$} & $296 \mathrm{kVA}$ & İndüksiyonlu ısıtma \\
{$[116]$} & $300 \mathrm{kVA}$ & Su işleme tesisi \\
{$[8]$} & $1 \mathrm{MVA}$ & Metro hattı \\
{$[117]$} & $1.5 \mathrm{MVA}$ & Demiryolu hattı \\
{$[118]$} & $4 \mathrm{MVA}$ & Trafo merkezi \\
{$[116]$} & $21-\mathrm{MVA}$ & Elektrik ark firını \\
{$[119]$} & $48 \mathrm{MVA}$ & Demiryolu hattı \\
\hline
\end{tabular}

\section{4. ÖGC'LERDE KULLANILAN KONTROL YÖNTEMLERININ KARŞILAŞTIRILMASI (THE COMPARISON OF CONTROL METHODS USED IN CPDS)}

i) Paralel ÖGC'lerin performansı yüksek derecede referans sinyali üretim tekniğine bağlıdır. Referans sinyali genellikle frekans veya zaman ortamında üretilir. Zaman ortamı tabanlı yöntemler hızlıdır ve frekans ortamı yöntemlerine göre uygulaması daha kolaydır. Örneğin zaman ortamı tabanlı anlık güç teoremi ve d-q eş zamanlı dönen eksen yöntemleri sayısal sinyal işleyicilerde kolaylıkla uygulandığından uygulamalarda sıklıkla tercih edildiği görülmüştür. Fakat bu yöntemler frekans tabanlı yöntemlere göre daha düşük hata tespit performansına sahiptir.

ii) Paralel ÖGC'ler genellikle akım kontrollü, gerilim kaynaklı evirici olduklarından dolayı akım ile ilgili güç kalitesi problemlerini (akım harmoniği, reaktif akım, yük dengesizliği vb.) kolaylıkla düzeltebilirler.
Ancak bu eviricilerde gerilim ile ilgili güç kalitesi problemlerinin (gerilim düşümü, çukuru/tepesi, dengesizliği, harmoniği vb.) düzeltilmesi, bazı özel topolojiler dişında oldukça zordur.

iii) Paralel ÖGC'ler kontrol stratejilerine göre doğrusal ve doğrusal olmayan akım kontrolü olmak üzere ikiye ayrılmaktadır [120]. Doğrusal olmayan kontrol şebekenin akımını gerilim kontrolü ile sağlar. Dinamik cevabı hızlıdır fakat sistem parametrelerine duyarlıdır. Dolayısıyla doğrusal akım kontrolü daha çok tercih edilmektedir.

iv) PI/PID denetleyici, rampa karşılaştırmalı akım kontrol, deadbeat tabanlı ve durum kestirimci gibi doğrusal akım kontrol yöntemlerinin en önemli avantajı geçici durumlardaki kararlı çalışmaları ve kolaylıkla tasarlanabilir olmalarıdır. Ancak bu yöntemler geçici durumlarda geç tepki verebilmektedir.

Histeresis kontrol, bulanık mantık tabanlı, yapay sinir ağları, kayan kip, Lyapunov fonksiyon gibi doğrusal olmayan akım kontrol yöntemleri ise geçici durumlarda hizlı tepki vermekte olup parametreleri optimize edildiğinde daha doğru cevap vermektedirler. Ancak bu yöntemlerin en büyük dezavantajı farklı çalışma koşullarda kararlılıklarını yitirmeleridir.

v) Paralel ÖGC'lerde en çok kullanılan kontrol yöntemi sinüzoidal dalga genişlik modülasyonu (SDGM) doğrusal akım PI kontrolüdür. SDGM‘lere alternatif olan histeresis modülasyonu değişken anahtarlama frekansı gerektirmekte ve bu durum büyük akım harmoniklerine neden olmaktadır. Diğer bir alternatif olan durum uzay DGM (DUDGM) modülasyonu $\mathrm{DA}$ bağ geriliminin kontrolünün verimini arttırır.

vi) DA bara geriliminin kontrolü, gerekli DSTATKOM ve AGF performansını elde etmek için kritik bir role sahiptir. Dinamik durumlarda, örneğin ani yük değişimi veya gerilim çukuru/tepesinde, DA bağ denetleyicisinin minimum gecikme süresiyle birlikte çok hızlı bir şekilde DA bağ gerilimini referans noktasina getirmesi gerekmektedir. PI tabanlı DA bağ gerilim denetleyicisinin uygulanması kolaydır ve bu yüzden araştırmacılar tarafından sıklıkla tercih 
edilmektedir. Ancak geçici durumlarda yavaş tepki vermesinden dolayı araştırmacılar tarafindan farklı DA bağ gerilim kontrolcüleri geliştirilmiştir. Bulanık mantık, bulanık-PID, yapay sinir ağları tabanlı kontrol, doğrusal kuadratik düzenleyici ve birleştirilmiş DA gerilim kompanzatörü bunlardan bazılarıdır [6].

\section{LITERATÜR TARAMASINDA INCELENEN CALISMALARIN SONUCLARI (RESULTS OF INVESTIGATED PAPERS DURING LITERATURE SURVEY)}

i) Paralel ÖGC'ler hem akım hem de gerilim kalitesi problemlerinin eş zamanlı olarak giderilmesinde yetersiz kalabilmektedir. $\mathrm{Bu}$ nedenle bazı çalışmalarda geçici ve ani güç kalitesi problemleri, kompanzatörün modu değiştirilerek yapılmaktadır. Bu amaç için paralel ÖGC'lerde farklı konfigürasyonlar önerilmiştir [110].

ii) Paralel ÖGC'ler çalışmalarında kırpışma ve kırpışmayla harmoniklerin aynı anda düzeltilmesi üzere çok az sayıda çalışma bulunmaktadır.

iii) Paralel ÖGC'ler ile gerilim çukuru/tepesi sırasında meydana gelen faz atlamaları, genelde göz önüne alınmamıștır.

iv) Paralel ÖGC'ler ile gerilimin faz açısının kontrolü üzerine yapılmış olan çalışmaların sayısının yetersiz olduğu görülmüştür.

v) Paralel ÖGC'ler ile asimetrik dengesizliğin (hem genlik hem de faz açısındaki dengesizlikler) kompanzasyonu üzerine yapılmış çalışma bulunmamaktadır.

vi) Paralel ÖGC'lerin güç devresinde çıkış filttresi için genelde L veya LC filtreleri kullanılmıştır. Ancak bu filtrelerin şebekede rezonans oluşturmalarından dolayı son yıllarda LCL filtreler daha yaygın olarak kullanılmaktadır. LCL filtrelerin şebeke ile rezonans oluşturmalarının önlenmesi ve eviricinin çıkış gerilimin anma değere sabit tutulması için evirici ve LCL filtrelerin kontrolü kapalı döngü olarak yapılmaktadir.

vii) Son yıllarda yüksek güçlü anahtarlama elemanlarının ve yüksek hızlı sayısal sinyal işaretçilerin geliștirilmesi ile birlikte, büyük güçlü ÖGC'lerin kurulumu artmıştır. $\mathrm{Bu}$ kurulumlara paralel olarak ÖGC teknolojisi için, çok-seviyeli evirici topolojilerinin kullanılması ve çok-fonksiyonlu kontrol yöntemlerinin geliştirilmesi yeni bir araştırma alanı oluşturmaktadır

\section{KAYNAKLAR}

1. Barghi Latran, M., Uzun Dağıtım Hatlarının Gerilim Kalitesi Sorunlarının Statik VAr Kompanzatör ile Giderilmesi, Yüksek Lisans Tezi, Hacettepe Üniversitesi, Fen Bilimleri Enstitüsü, 2012.

2. Sermon, R.C., "An Overview of Power Quality Standards and Guidelines from the End-User's
Point-of-View", Rural Electric Power Conference, San Antonio, B1/1 - B1/5, 8-10 Mayis 2005.

3. Enerji Piyasası Düzenleme Kurumu, "Elektrik Dağıtımı ve Perakende Satışına İlişkin Hizmet Kalitesi Yönetmeliği”, 21 Aralık 2012.

4. Deniz, E.,Tuncer S., Gençoğlu T. M., E., "ÜçSeviyeli Diyot Kenetlemeli İnverterli STATCOM Kullanılarak Bir Dağıtım Sisteminde Gerilim Regülasyonu", 5. Uluslararası İleri Teknolojiler Sempozyumu, 13-15 Mayıs 2009, Karabük, Türkiye.

5. Deniz, E., Çöteli, R., Dandıl, B., Tuncer, S., "Üç-Seviyeli H-Köprü Evirici Tabanlı D-Statkom'un Tasarımı ve Gerçekleştirilmesi”, Gazi Üniv. Müh. Mim. Fak. Der., Cilt 26, No 2, 289-298, 2011.

6. Teke, A., Latran, M.B., "Review of Multifunctional Inverter Topologies and Control Schemes used in Distributed Generation Systems", Journal of Power Electronics, Cilt 14, No 2, 324-340, Mart 2014.

7. Singh, B., Saha, R., Chandra, A., Al-Haddad, K., "Static Synchronous Compensators (STATCOM): A Review", IET Power Electronics, Cilt 2, No 4, 297-324, Temmuz 2009.

8. Güç Kalitesi Milli Projesi bilgi notu, http://www.guckalitesi.gen.tr.

9. Çöteli, R., Aydoğmuş, Z., "DGM-Statcom ile Reaktif Güç Kompanzasyonu", Politeknik Dergisi, Cilt 10, No 2, 123-128, 2007.

10. Singh, B., Arya, S.R., "Back-Propagation Control Algorithm for Power Quality Improvement Using DSTATCOM", IEEE Transactions on Industrial Electronics, Cilt 61, No.3, 1204 1212, Mart 2014.

11. Kamatchi Kannan, V., Rengarajan, N., "Investigating the Performance of Photovoltaic Based DSTATCOM using Icos $\varphi$ Algorithm", International Journal of Electrical Power \& Energy Systems, Cilt 54, 376-386, Ocak 2014.

12. Shahnia, F., Ghosh, A., Ledwich, G., Zare, F., "Voltage Unbalance Improvement in Low Voltage Residential Feeders with Rooftop PVs Using Custom Power Devices", International Journal of Electrical Power \& Energy Systems, Cilt 55, 362-377, Subat 2014.

13. Chen, C.-S., Lin, C.-H., Hsieh, W.-L., Hsu, C.-T., "Enhancement of PV Penetration with DSTATCOM in Taipower Distribution System", IEEE Transactions on Power Systems, Cilt 28, No 2, 1560-1567, May1s 2013.

14. Singh, B., Arya, S.R., "Implementation of Single-Phase Enhanced Phase-Locked Loop-Based Control Algorithm for Three-Phase DSTATCOM", IEEE Transactions on Power Delivery, Cilt 28, No 3, 1516 - 1524, Temmuz 2013.

15. Singh, B., Arya, S.R., "Adaptive Theory-Based Improved Linear Sinusoidal Tracer Control 
Algorithm for DSTATCOM", IEEE Transactions on Power Electronics, Cilt 28, No 8, 3768 - 3778, Ağustos 2013.

16. Singh, B., Arya, S.R., "Composite Observer-Based Control Algorithm for Distribution Static Compensator in Four-Wire Supply System", IET Power Electronics, Cilt 6, No 2, 251-260, Şubat 2013.

17. Arya, S.R., Singh, B., "Implementation of Distribution Static Compensator for Power Quality Enhancement Using Learning Vector Quantisation", IET Generation, Transmission \& Distribution, Cilt 7, No 11, 1244-1252, Kasım 2013.

18. Mahmud, M.A., Pota, H.R., Hossain, M.J., "Nonlinear DSTATCOM Controller Design for Distribution Network with Distributed Generation to Enhance Voltage Stability", International Journal of Electrical Power \& Energy Systems, Cilt 53, 974-979, Aralık 2013.

19. Kumar, P., Kumar, N., Akella, A.K., "Modeling and Simulation of Different System Topologies for DSTATCOM", AASRI Conference on Parallel and Distributed Computing and Systems, Cilt 5, 2013, 249-261.

20. Wolfs, P., Amanullah M., "Improvements to LV Distribution System PV Penetration Limits Using a Dstatcom with Reduced DC Bus Capacitance", IEEE Power and Energy Society General Meeting, Vancouver, 21-25 Temmuz 2013, 1-5.

21. Kumar, C., Mishra, M.K., "A modified DSTATCOM Topology with Reduced VSI Rating, DC Link Voltage, and Filter Size", International Conference on Clean Electrical Power, Alghero, 11-13 Haziran 2013, 325-331.

22. Karanki, S.B., Geddada, N.; Mishra, M.K.; Kumar, B.K., "A DSTATCOM Topology with Reduced DC-Link Voltage Rating for Load Compensation with Nonstiff Source", IEEE Transactions on Power Electronics, Cilt 27, No 3, 120-1211, Mart 2012.

23. Zaveri, T., Bhalja, B., Zaveri, N., "Comparison of Control Strategies for DSTATCOM in Three-Phase, Four-Wire Distribution System for Power Quality Improvement Under Various Source Voltage and Load Conditions", International Journal of Electrical Power \& Energy Systems, Cilt 43, No 1, 582-594, Aralık 2012.

24. Zaveri, T., Bhalja, B., Zaveri, N., "Load Compensation Using DSTATCOM in Three-Phase, Three-Wire Distribution System Under Various Source Voltage and Delta Connected Load Conditions", International Journal of Electr. Power \& Energy Systems, Cilt 41, No 1, 34-43, Ekim 2012.

25. Karmiris, G., Tsengenes, G., Adamidis, G., "A Multifunction Control Scheme for Current Harmonic Elimination and Voltage Sag Mitigation Using a Three Phase Three Level Flying Capacitor
Inverter", Simulation Modelling Practice and Theory, Cilt 24, 15-34, Mayis 2012.

26. Singh, B., Arya, S.R., Chandra, A., Al-Haddad, K., "Implementation of Adaptive Filter Based Control Algorithm for Distribution Static Compensator", IEEE Annual Meeting on Industry Applications Society, Las Vegas, 7-11 Ekim 2012, $1-8$.

27. Arya, S.R., Singh, B., Chandra, A., Al-Haddad, K., "Control of Shunt Custom Power Device Based on Anti-Hebbian Learning Algorithm", $\mathbf{3 8}^{\text {th }}$ IEEE Annual Conference on Industrial Electronics Society, Montreal, 25-28 Ekim 2012, $1246-1251$.

28. Singh, B., Arya, S.R., "Software PLL Based Control Algorithm for Power Quality Improvement in Distribution System", (IICPE), $\mathbf{5}^{\text {th }}$ IEEE India International Conference on Power Electronics, Delhi, 6-8 Aralık 2012, 1-6.

29. Arya, S.R., Singh, B., Chandra, A., AI-Haddad, K., "Control of DSTATCOM Using Adjustable Step Least Mean Square Control Algorithm", $\mathbf{5}^{\text {th }}$ IEEE Fifth Power India Conference, Murthal, 19-22 Aralık 2012, 1 - 6 .

30. Bukata, B.B., Li Y., "A Novel Model-Free Prediction of Power Quality Problems via DSTATCOM", $\mathbf{1 8}^{\text {th }}$ International Conference on Automation and Computing, Loughborough, 7-8 Eylül 2012, $1-6$.

31. Reddy, J.G.P., Reddy, K.R., "Power quality Improvement Using Neural Network Controller Based Cascaded H-Bridge Multilevel Inverter Type D-STATCOM", International Conference on Computer Communication and Informatics, Coimbatore, 10-12 Ocak 2012, 1 - 6.

32. Gawande, S.P., Khan, S., Ramteke, M.R., "Voltage Sag Mitigation Using Multilevel Inverter Based Distribution Static Compensator (DSTATCOM) in Low Voltage Distribution System", $5^{\text {th }}$ India International Conference on Power Electronics, Delhi, 6-8 Aralık 2012, 1-6.

33. Bhattacharjee, C., Roy, A.K., Roy, B.K., "Improvement of Available Load Voltage for a Constant Speed WECS Coupled with Fuzzy-Controlled DSTATCOM”, $\quad \mathbf{1 5}^{\text {th }}$ International Conference on Harmonics and Quality of Power, Hong Kong, 17-20 Haziran 2012, 637-641.

34. Nair, D., Nambiar, A., Raveendran, M., Mohan, N.P., Sampath, S., "Mitigation of Power Quality Issues Using DSTATCOM", International Conference on Emerging Trends in Electrical Engineering and Energy Management, Chennai, 13-15 Aralik 2012, 65 - 69.

35. Singh, B., Arya, S.R., "Admittance Based Control Algorithm for DSTATCOM in Three Phase Four Wire System", $2^{\text {th }}$ International Conference on Power, Control and Embedded Systems, Allahabad, 17-19 Aralık 2012, 1-8.

36. Chen, L., Cheng, X., Yang, K., Zhang, Y., Chen, 
G., "DC-bus Voltage Control Strategy of DSTATCOM Using Modulation Ratio Regulation for Start-Up Process", IEEE International Symp. Industrial Electronics, Hangzhou, 28-31 Mayis 2012, 275-279.

37. Ramesh, J., Sudhakaran, M., "Enhancement of Power Quality Using Three Phase DSTATCOM for Variable Load", International Conference on Emerging Trends in Electrical Engineering and Energy Management, Chennai, 13-15 Aralık 2012, $88-92$.

38. Aggarwal, M., Gupta, S.K., Singh, M., "Integration of Wind Generation System in Low Voltage Distribution System", IEEE $5^{\text {th }}$ India International Conference on Power Electronics, Delhi, 6-8 Aralık 2012, 1 - 6 .

39. Lin, C.H., Chen, C. S., Hsieh, W. L., Hsu, C. T., Chuang, H. J., Ho, C.Y., "Optimization of Photovoltaic Penetration with DSTATCOM in Distribution Systems", IEEE International Conference on Power System Technology, Auckland, Ekim 30 2012-Kasım 2 2012, 1 - 6.

40. Kumar, C., Mishra, M.K., "A Control Algorithm for Flexible Operation of DSTATCOM for Power Quality Improvement in Voltage and Current Control Mode", IEEE International Conference on Power Electronics, Drives and Energy Systems, Bengaluru, 16-19 Aralık 2012, 1 - 6.

41. Mahmud, M.M.A., Pota, H.R., Hossain, M.J., "Partial Feedback Linearizing Controller Design for a DSTATCOM to Enhance Voltage Stability of Distribution Network with Distributed Generation", IEEE International Conference on Power System Technology, Auckland, Ekim 30 2012-Kasim 2 2012, 1-6.

42. Arya, S.R., Singh, B., Chandra, A., Al-Haddad, K., "Power Factor Correction and Zero Voltage Regulation in Distribution System Using DSTATCOM", IEEE International Conference on Power Electronics, Drives and Energy Systems, Bengaluru, 16-19 Aralık 2012, 1-6.

43. Singh, B., Solanki, J., "Load Compensation for Diesel Generator-Based Isolated Generation System Employing DSTATCOM", IEEE Transactions on Industry Applications, Cilt 47, No 1, 238 - 244, Ocak-Şubat 2011.

44. Zaveri, T., B.R., Bhalja, Zaveri, N., "A Novel Approach of Reference Current Generation for Power Quality Improvement in Three-Phase, Three-Wire Distribution System Using DSTATCOM", International Journal of Electrical Power \& Energy Systems, Cilt 33, No 10, 1702-1710, Aralık 2011.

45. Jazebi, S., Hosseinian, S.H., Vahidi, B., "DSTATCOM Allocation in Distribution Networks Considering Reconfiguration Using Differential Evolution Algorithm", Energy Conversion and Management, Cilt 52, No 7, 2777-2783, Temmuz 2011.

46. Luo, A., Fang, L., Xu, X., Peng, S., Wu, C., Fang,
H., "New Control Strategy for DSTATCOM Without Current Sensors and its Engineering Application", International Journal of Electrical Power \& Energy Systems, Cilt 33, No 2, 322-331, Şubat 2011.

47. Mitra, P., Venayagamoorthy, G.K., "An Adaptive Control Strategy for DSTATCOM Applications in an Electric Ship Power System", IEEE Transactions on Power Electronics, Cilt 25, No 1, 95 - 104, Ocak 2010.

48. Gupta, R., Ghosh, A., Joshi, A., "Multiband Hysteresis Modulation and Switching Characterization for Sliding Mode Controlled Cascaded Multilevel Inverter", IEEE Transactions on Industrial Electronics, Cilt 57, No 7, 2344-2353, Temmuz 2010.

49. Srikanthan S., Mahesh K.M., "DC Capacitor Voltage Equalization in Neutral Clamped Inverters for DSTATCOM Application", IEEE Transactions on Industrial Electronics, Cilt 57, No 8, 2768 - 2775, Ağustos 2010.

50. Valderrábano, A., Ramirez, M.J., "DStatCom Regulation by a Fuzzy Segmented PI Controller", Electric Power Systems Research, Cilt 80, No 6, 707-715, Haziran 2010.

51. Segundo-Ramirez, J., Medina, A., Ghosh, A., Ledwich, G., "Stability Analysis Based on Bifurcation Theory of the DSTATCOM Operating in Current Control Mode", IEEE Transactions on Power Delivery, Cilt 24, No 3, 1670 - 1678, Temmuz 2009.

52. Mishra, M.K., Karthikeyan, K., "A Fast-Acting DC-Link Voltage Controller for Three-Phase DSTATCOM to Compensate AC and DC Loads", IEEE Transactions on Power Delivery, Cilt 24, No 4, 2291-2299, Ekim 2009.

53. George, V., Mishra, M.K., "Design and Analysis of User-Defined Constant Switching Frequency Current Control Based Four Leg DSTATCOM", IEEE Transactions on Power Electronics, Cilt 24, No 9, 2148-2158, Eylül 2009.

54. Srikanthan, S., Mishra, M.K., Rao, R.K.V., "Improved Hysteresis Current Control of Three-Level Inverter for Distribution Static Compensator Application", IET Power Electronics, Cilt 2, No 5, 517-526, Eylül 2009.

55. Gupta, R., Ghosh, A., Joshi, A., "Characteristic Analysis for Multisampled Digital Implementation of Fixed Switching Frequency Closed-Loop Modulation of Voltage-Source Inverter", IEEE Transactions on Industrial Electronics, Cilt 56, No 7, 2382-2392, Temmuz 2009.

56. Singh, B., Solanki, J., "A Comparison of Control Algorithms for DSTATCOM", IEEE Transactions on Industrial Electronics, Cilt 56, No 7, 2738 - 2745, Temmuz 2009.

57. Singh, B., Jayaprakash, P., Kothari, D.P., "A T-Connected Transformer and Three-leg VSC Based DSTATCOM for Power Quality Improvement", IEEE Transactions on Power 
Electronics, Cilt 23, No6, 2710-2718, Kasim 2008.

58. Shukla, A., Ghosh, A., Joshi, A., "Control Schemes for DC Capacitor Voltages Equalization in Diode-Clamped Multilevel Inverter-Based DSTATCOM", IEEE Transactions on Power Delivery, Cilt 23, No 2, 1139 - 1149, Nisan 2008.

59. Shukla, A., Joshi, A., "State Feedback Control of Multilevel Inverters for DSTATCOM Applications", IEEE Transactions on Power Delivery, Cilt 22, No 4, 2409-2418, Ekim 2007.

60. Eldery, M.A., El-Saadany, E.F., Salama, M.M.A., "DSTATCOM Effect on the Adjustable Speed Drive Stability Boundaries", IEEE Trans. Power Delivery, Cilt 22, No 2, 1202 - 1209, Nisan 2007.

61. Shukla, A., Ghosh, A., Joshi, A., "Hysteresis Current Control Operation of Flying Capacitor Multilevel Inverter and Its Application in Shunt Compensation of Distribution Systems", IEEE Transactions on Power Delivery, Cilt 22, No 1, 396-405, Ocak 2007.

62. Gupta, R., Ghosh, A., "Frequency-domain Characterization of Sliding Mode Control of an Inverter Used in DSTATCOM Application", IEEE Transactions on Circuits and Systems I: Regular Papers, Cilt 53, No 3, 662-676, Mart 2006.

63. Freitas, W., Wilsun $\mathrm{Xu}$, Sato, F., "Impacts of AC Generators and DSTATCOM Devices on the Dynamic Performance of Distribution Systems", IEEE Transactions on Power Delivery, Cilt 20, No 2, 1493-1501, Nisan 2005.

64. Elnady, A., Salama, M.M.A., "Unified Approach for Mitigating Voltage Sag and Voltage Flicker Using the DSTATCOM", IEEE Transactions on Power Delivery, Cilt 20, No 2, 992- 1000, Nisan 2005.

65. Ghosh, A., Joshi, A., "The Concept and Operating Principles of a Mini Custom Power Park", IEEE Transactions on Power Delivery, Cilt 19, No 4, 1766 - 1774, Ekim 2004.

66. Mishra, M.K., Ghosh, A., Joshi, A., "Operation of a DSTATCOM in Voltage Control Mode", IEEE Transactions on Power Delivery, Cilt 18, No 1, 258 - 264, Ocak 2003.

67. Ledwich, G., Ghosh, A., "A Flexible DSTATCOM Operating in Voltage or Current Control Mode", IEE Generation, Transmission and Distribution, Cilt 149, No 2, 215 - 224, Mar 2002.

68. Bilgin, H.F., Ermis, M., "Design and Implementation of a Current-Source Converter for Use in Industry Applications of D-STATCOM", IEEE Transactions on Power Electronics, Cilt 25, No 8, 1943-1957, Ocak 2010.

69. Bilgin, H.F., Ermis, M., Kose, K.N., A., Cetin, Cadirci, I., Acik, A., Demirci, T., Terciyanli, A., Kocak, C., Yorukoglu, M., "Reactive-Power Compensation of Coal Mining Excavators by Using a New-Generation STATCOM", IEEE
Transactions on Industry Applications, Cilt 43, No 1, 97-110, Ocak-Şubat 2007.

70. ABB Application Notes, "Power Quality Solutions STATCOM, $100 \mathrm{kVAr}$ to 100 MVAr Dynamic Reactive Power Compensation", www.abb.com.

71. ABB Review, "Stabilizing Grids and Enabling Renewable Power Generation with PCS 6000 STATCOM", www.abb.com.

72. A Customer Magazine of ABB Group, “STATCOM Solutions", April 2013

73. ABB Application Notes, 'PCS100 - ABB's Innovative Power Electronics Solutions for the Mining Industry", www.abb.com.

74. Şenyurt, Ö., Elektrik Tesislerinde Harmonikler, Yüksek Lisans Tezi, Fen bilimleri Enistitüsü, Gazi Üniversitesi, Mayıs 2005.

75. Dugan, R.C., McGranaghan, M.F., Santoso, S., Beaty H.W., "Electrical Power Systems Quality", McGraw-Hill, 1 Mar 2003, 528 sayfa.

76. Tan, A., Akım Kaynaklı Çevirgece Dayalı Endüksiyon Fırını için Güç Kalitesi Kompanzasyon Sistemlerinin Modellenmesi ve Analizi, Yüksek Lisans Tezi, Çukurova Üniversitesi, Fen Bilimleri Enstitüsü, 2011.

77. Atacak, İ., Duran, F., Ö., Bay, F., "Bulanık-PI Denetimli Üç Fazlı Paralel Aktif Güç Filtresinin Tasarımı", 5. Uluslararası İleri Teknolojiler Sempozyumu, Karabük, Türkiye, 13-15 Mayıs 2009.

78. Tang, X., Tsang, K.M., Chan, W.L., "Power Conditioning System for Grid-Connected Photovoltaic System", Solar Energy, Cilt 96, 187-193, Ekim 2013.

79. Zhou, Z., Liu, Y., "Pre-Sampled Data Based Prediction Control for Active Power Filters", International Journal of Electrical Power \& Energy Systems, Cilt 37, No 1, 13-22, May1s 2012.

80. Karuppanan, P., Mahapatra, K.K., "PI and Fuzzy Logic Controllers for Shunt Active Power Filter-A Report", ISA Transactions, Cilt 51, No 1, 163-169, Ocak 2012.

81. Zaveri, N., Chudasama, A., "Control Strategies for Harmonic Mitigation and Power Factor Correction Using Shunt Active Filter Under Various Source Voltage Conditions", International Journal of Electrical Power \& Energy Systems, Cilt 42, No 1, 661-671, Kasim 2012.

82. Ketabi, A., Farshadnia, M., Malekpour, M., Feuillet, R., "A New Control Strategy for Active Power Line Conditioner (APLC) Using Adaptive Notch Filter", International Journal of Electrical Power \& Energy Systems, Cilt 47, 31-40, May1s 2013.

83. Merabet, L., Saad, S., Abdeslam, D.O., Omeiri, A., "A Comparative Study of Harmonic Currents Extraction by Simulation and Implementation", International Journal of Electrical Power \& Energy Systems, Cilt 53, 507-514, Aralık 2013. 
84. Panda, G., Ray, P.K., Puhan, P.S., Dash, S.K., "Novel Schemes Used for Estimation of Power System Harmonics and Their Elimination in A Three Phase Distribution System", International Journal of Electrical Power \& Energy Systems, Cilt 53, 842-856, Aralık 2013.

85. Islam, F.R., Pota, H.R., "Virtual Active Filters for HVDC Networks Using V2G Technology", International Journal of Electrical Power \& Energy Systems, Cilt 54, 399-407, Ocak 2014.

86. Lu, W., Li, C., Xu, C., "Sliding Mode Control of a Shunt Hybrid Active Power Filter Based on the Inverse System Method", International Journal of Electrical Power \& Energy Systems, Cilt 57, 39-48, May1s 2014.

87. Garces, A., Molinas, M., Rodriguez, P., "A Generalized Compensation Theory for Active Filters Based On Mathematical Optimization in ABC Frame", Electric Power Systems Research, Cilt 90, 1-10, Eylül 2012.

88. Mesbahia, N., Ouaria, A., Abdeslamb, D.O., Djamahc, T., Omeiri, A., "Direct Power Control of Shunt Active Filter Using High Selectivity Filter (HSF) Under Distorted or Unbalanced Conditions", Electric Power Systems Research, Cilt 108, 113-123, Mart 2014.

89. Ramos, G.A., Castello', R.C., Olm, J.M., "Analysis and Design of a Robust Odd-Harmonic Repetitive Controller For an Active Filter Under Variable Network Frequency", Control Engineering Practice, Cilt 20, No 9, 895-903, Eylül 2012.

90.Zhao, W., Chen, R., Luo, A., "Recursive Integral with Fuzzy Control Method used in Shunt Hybrid Active Power Filter", Energy Procedia, Cilt 16, Part C, 1753-1759, 2012.

91. Bouzid, A.M., Benghanem, M., Hamane, B., Belabbes, A., Bouhamida, M., Draou, A., "Current Control of the Isolated Self-Excited Induction Generator using Shunt Active Filter", Energy Procedia, Cilt 18, 349-358, 2012.

92. Belaidi, R., Haddouche, A., Guendouz, H., "Fuzzy Logic Controller Based Three-Phase Shunt Active Power Filter for Compensating Harmonics and Reactive Power under Unbalanced Mains Voltages", Energy Procedia, Cilt 18, 560-570, 2012.

93. Rahmani, S., Mendalek, N., Member, Al-Haddad, K., "Experimental Design of a Nonlinear Control Technique for Three-Phase Shunt Active Power Filter", IEEE Transactions on Industrial Electronics, Cilt 57, No 10, 3364 - 3375, Ekim 2010.

94. Silva, C.H.D., Pereira, R.R., Silva, L.E.B.D., Torres, G.L., Bose, B.K., Ahn, S.U., "A Digital PLL Scheme for Three-Phase System Using Modified Synchronous Reference Frame”, IEEE Transactions on Industrial Electronics, Cilt 57, No 11, 3814-3821, Kasim 2010.

95.Zeng, F.P., Tan, G.H., Wang, J.Z., Ji, Y.C.,
"Novel Single-Phase Five-Level Voltage-Source Inverter for the Shunt Active Power Filter", IET Power Electronics, Cilt 3, No 4, 480-489, Temmuz 2010.

96. Odavic, M., Biagini, V., Zanchetta, P., Sumner, M., Degano, M., "One-Sample-Period-Ahead Predictive Current Control for High Performance Active Shunt Power Filters", IET Power Electronics, Cilt 4, No 4, 414-423, Nisan 2011.

97. Freijedo, F.D., Yepes, A.G., J., Malvar, Lopez, O., Fernandez-Comesana, P., Vidal, A., Doval-Gandoy, J., "Frequency Tracking of Digital Resonant Filters for Control of Power Converters Connected to Public Distribution Systems", IET Power Electronics, Cilt 4, No 4, 454 - 462, Nisan 2011.

98. Ribeiro, R.L.D.A., Azevedo, C.C.D., Sousa, R.M.D., "A Robust Adaptive Control Strategy of Active Power Filters for Power-Factor Correction, Harmonic Compensation, and Balancing of Nonlinear Loads", IEEE Transactions on Power Electronics, Cilt 27, No 2, 718 - 730, Şubat 2012.

99. Rahmani, S., Hamadi, A., Al-Haddad, K., "A Lyapunov-Function-Based Control for a Three-Phase Shunt Hybrid Active Filter", IEEE Transactions on Industrial Electronics, Cilt 59, No 3, 1418 - 1429, Mart 2012.

100. Liu, J., Zanchetta, P., Degano, M., Lavopa, E., "Control Design and Implementation for High Performance Shunt Active Filters in Aircraft Power Grids", IEEE Transactions on Industrial Electronics, Cilt 59, No 9, 3604 - 3613, Eylül 2012.

101. Terciyanli, A., Avci, T., Yılmaz, I., Ermis, C., Nadir Kose, K., Açik, A., Sabri Kalaycioglu, A., Akkaya, Y., Çadırcı, I., Ermiş, M., "A Current Source Converter-Based Active Power Filter for Mitigation of Harmonics at the Interface of Distribution and Transmission Systems", IEEE Transactions on Industry Applications, Cilt 48, No 4, 1374-1386, Temmuz-Ağustos 2012.

102. Hamad, M.S., Gadoue, S.M., Williams, B.W., "Harmonic Compensation of a Six-Pulse Current Source Controlled Converter Using Neural Network-Based Shunt Active Power Filter", IET Power Electronics, Cilt 5, No 6, 747 - 754, Temmuz 2012.

103. Suresh, Y., Panda, A.K., Suresh, M., "Real-Time Implementation of Adaptive Fuzzy Hysteresis Band Current Control Technique for Shunt Active Power Filter", IET Power Electronics, Cilt 5, No 7, 1188-1195, Ağustos 2012.

104. Ramos, G.A., Costa-Castelló, R., "Power Factor Correction and Harmonic Compensation Using Second-Order Odd-Harmonic Repetitive Control", IET Control Theory \& Applications, Cilt 6, No 11, 1633-1644, Temmuz 2012.

105. Hamad, M.S., Masoud, M.I., Williams, B.W., Finney, S., "Medium Voltage 12-Pulse Converter: AC Side Compensation Using a Shunt Active 
Power Filter in a Novel Front End Transformer Configuration", IET Power Electronics, Cilt 5, No 8, 1315-1323, Eylül 2012.

106. Mikkili, S., Panda, A.K., "Types-1 and -2 Fuzzy Logic Controllers-Based Shunt Active Filter Id-Iq Control Strategy with Different Fuzzy Membership Functions for Power Quality Improvement Using RTDS Hardware", IET Power Electronics, Cilt 6, No 4, 818-833, Nisan 2013.

107. Biagini, V., Zanchetta, P., Odavic, M., Sumner, M., Degano, M., "Control and Modulation of a Multilevel Active Filtering Solution for Variable Speed Constant Frequency More Electric Aircraft Grids", IEEE Trans. Industrial Informatics, Cilt 9, No 2, 600-608, Mayıs 2013.

108. Zanchetta, P., Degano, M., Liu, J., Mattavelli, P., "Iterative Learning Control with Variable Sampling Frequency for Current Control of Grid-Connected Converters in Aircraft Power Systems", IEEE Trans. on Industry Applications, Cilt 49, No 4, 1548-1555, Temmuz-Ağustos 2013.

109. Fujita, H., Akagi, H., "Voltage-Regulation Performance of a Shunt Active Filter Intended for Installation on a Power Distribution System", IEEE Transactions on Power Electronics, Cilt 22, No 3, 1046-1053, May1s 2007.

110. Lee, T.L., Wang, Y.C., Li, J.C., "Design of a Hybrid Active Filter for Harmonics Suppression in Industrial Facilities", International Conference on Power Electronics and Drive Systems, Taipei, 2-5 Kasım 2009, 121 - 126.

111. Menniti, D., Burgio, A., Sorrentino, N., Pinnarelli, A., "Implementation of the shunt harmonic voltages compensation approach", Electric Power Systems Research, Cilt 81, No 3, 798-804, Mart 2011.

112. Tlusty, J., Santarius, P., Valouch, V., Skramlık, J., "Optimal Control of Shunt Active Power Filters in Multibus Industrial Power Systems for Harmonic Voltage Mitigation", Mathematics and Computers in Simulation, Cilt 71 , No 4-6,
369-376, Haziran 2006.

113. Burgio, A., Menniti, D., Sorrentino, N., Pinnarelli, A., Brusco, G., "An Active Resonance Damper Which Avoids the Estimation of the Line Characteristic Impedance", Electric Power Systems Research, Cilt 107, 16-20, Şubat 2014.

114. Eida, A., Abdel-Salam, M., El-Kishky, H., El-Mohandes, T., "Active Power Filters for Harmonic Cancellation in Conventional and Advanced Aircraft Electric Power Systems", Electric Power Systems Research, Cilt 79, No 1, 80-88, Ocak 2009.

115. ABB Apllication Notes, "Power Quality Filter Active Filtering Guide", www.abb.com.

116. Akagi, H., "Modern active filters and traditional passive filters", Bulletın of the Polish Academy of Sciences, Technical Sciences, Cilt 54, No. 3, 2006.

117. Fuchs, H.D., "Development and Implementation of a $1.5 \mathrm{MW}$ Inverter and Active Power Filter System for the Injection of Regenerated Energy in a Spoornet Traction Substation", Yüksek Lisans Tezi, Stellenbosch Üniversitesi, 2005.

118. Terciyanli, A., Avci, T., Yilmaz, I., Ermis, C., Kose, N., Acik, A., Kalaycioglu, A., Akkaya, Y., Cadirci, I., Ermis, M., "A Current Source Converter based Active Power Filter for mitigation of harmonics at the interface of distribution and transmission systems", Transactions on Industry Applications, Cilt 48, No 4, 1374-1386, Temmuz/ Ağustos 2012.

119. Akagi, H., "New Trends in Active Filters for Power Conditioning", IEEE Transactions on Industry Applications, Cilt 32, No 6, 1312-1322, Kasım /Aralık 1996.

120. Zeng Z., Yang H., Zhao R., Cheng C., "Topologies and Control Strategies of Multi-Functional Grid-Connected Inverters for Power Quality Enhancement: A Comprehensive Review", Renewable and Sustainable Energy Reviews, Cilt 24, 223-270, Ağustos 2013. 
